Background: Nitric oxide (NO) is an important physiological mediator of vascular tone and is involved in pathophysiology of septic shock. Although plasma nitrite is a stable end product of NO oxidation derived from endogenous NO, the plasma nitrite level is also easily affected by the in take of various foods, bacterial products and renal functional status.

Aims: We propose an excellent alternative assay technique for measuring endogenous NO production. Methods: We measured the nitrite level in cultured vascular smooth muscle cells (SMC) treated with serum obtained from patients with sepsis (4 patients), by means of a chemiluminescence detector.

Results: The nitrite concentrations in such cells were significantly higher as compared to those in the cells treated with normal serum. Moreover, the increased nitrite levels in the SMC treated with the sera obtained from patients with sepsis were completely inhibited by $L$-n itroarginine $(1 \mathrm{~m} \mathrm{~mol} / \mathrm{L})$, a nitric oxide synthase in hibitor.

Conclusion: These data suggest that th is assay method enable us to know the ability of endogenous NO production in each patient.

Key words: Sepsis, NO

\section{Sera from patients with sepsis induce nitric oxide production in vascular smooth muscle cells}

\author{
Hiroshi Fujitaa,2,CA, Junji Tomiyama ${ }^{1}$, Hideki Kudo ${ }^{1}$, \\ Ikuo Morita ${ }^{2}$ and Sei-itsu Murota ${ }^{2}$
} ${ }^{1}$ Department of Internal
Metropolitan Bokutou G
Koutoubashi, Sumida-ku,
and ${ }^{2}$ Section of Cellular
Graduate School, Tokyo
University, 1-5-45 Yushi
Japan
CACorresponding Author
Tel: +81-3-3633-6151
Fax: +81-3-3633-6173
Email: fujita@ec.mbn.or.jp

'Department of Internal Medicine, Tokyo

Metropolitan Bokutou General Hospital, 4-23-15

Koutoubashi, Sumida-ku, Tokyo 130-8575, Japan, and ${ }^{2}$ Section of Cellular Physiological Chemistry, , Tokyo Medical and Dental University, 1-5-45 Yushima, Bunkyo-ku, Tokyo 113,

\section{Introduction}

Various factors are involved in the pathogenesis of septic shock. Among them, recent interest has been centred on the nitric oxide (NO) pathway. ${ }^{1}$ Evidence for its involvement stems from the observation that a specific NO synthase inhibitor prevented endotoxininduced hypotension in an experimental model ${ }^{2}$ and that in patients with septic shock resistant to the treatment with a certain NOS inhibitor and to an increase in blood pressure. ${ }^{3}$ In order to determine the influence of sepsis on the endogenous NO production in humans, plasma nitrite levels were conventionally measured, because nitrite is a very stable oxidation product. However, a drawback of this method is that plasma nitrite is derived from not only endogenous NO, but also from various foods and bacterial products. In addition, nitrite levels are easily affected by the renal functional status. ${ }^{4}$ Therefore, we consider, it is almost impossible to measure endogenously produced NO alone in the blood. We tried to measure the endogenous NO producing activity of patients with sepsis by means of cultured vascular smooth muscle cells (SMC). Sera from patients with sepsis induced NO production in the SMC, but those from control subjects did not.

These data suggest that our assay system can be useful for the evaluation of the endogenous NO producing activity in pathological conditions such as sepsis.

\section{Patients and methods}

\section{Patient}

Four patients ( 1 male and 3 female), aged 47-68 years, who were diagnosed as having sepsis were recruited in the study. Patients were judged clinically to have septicaemia if they had a high fever $\left(>38.5^{\circ} \mathrm{C}\right)$ and tachycardia (>110/min). All the patients had the haematological malignancies ( 1 case of acute lymphoblastic leukemia, 1 of myelodysplastic syndrome and 2 of chronic myeloblastic leukemia), as shown in Table 1. Blood samples were obtained within 24 hours of the diagnosis of septicaemia. Serum was separated immediately by centrifugation, frozen, and kept at $-80^{\circ} \mathrm{C}$ until analysis.

\section{Reagents}

L-nitroarginine and D-nitroarginine were purchased from Sigma Co. Ltd (MO).

\section{Cell culture}

Bovine vascular SMCs were isolated from a carotid artery and cultured as described previously. ${ }^{5}$ The cells were grown in modified Eagle's medium (MEM; GIBCO, NY) supplemented with $10 \%$ foetal calf serum (JRH Biosciences, Lenexa, KS), and used between passages 11 and 21. For the studies reported 
Table 1. Characteristics of patients with sepsis

\begin{tabular}{lllcccc}
\hline & Age/sex & Diseases & $\begin{array}{c}\text { Blood pressure } \\
(\mathrm{mm} \mathrm{Hg})\end{array}$ & $\begin{array}{c}\text { WBC }(/ \mu \mathrm{l}) / \text { Seg } \\
(\%)\end{array}$ & $\begin{array}{c}\text { CRP } \\
(\mathrm{mg} / \mathrm{ml})\end{array}$ & $\begin{array}{c}\text { Endotoxin } \\
(\mathrm{pg} / \mathrm{ml})\end{array}$ \\
\hline Case 1 & 68/M & MDS (RAEB) & $118 / 70$ & $600 / 26$ & 16.4 & 26.3 \\
Case 2 & 48/F & CML & $130 / 72$ & $6300 / 0$ & 3.8 & $\mathrm{NE}$ \\
Case 3 & 47/F & ALL & $110 / 70$ & $3500 / 8$ & 1.1 & $\mathrm{NE}$ \\
Case 4 & 68/F & CML & $108 / 64$ & $8800 / 64$ & 6.2 & 17.2 \\
\hline
\end{tabular}

WBC: white blood cells, Seg: segmented neutrophils, CRP: C reactive protein. MDS: myelodysplastic syndrome, RAEB: refractory anemia with excess of blast, ALL: acute lymphoblastic leukemia, CML: chronic myeloblastic leukemia.

here, the cells were inoculated into wells $(16 \mathrm{~mm}$, $200 \mathrm{~mm}^{2}$ ) (Iwaki Glass, Tokyo) containing MEM supplemented with $10 \%$ FCS and maintained at $37^{\circ} \mathrm{C}$ in an incubator under a humidified atmosphere of $95 \%$ air and $5 \% \mathrm{CO}_{2}$.

\section{NO measurement}

Confluent SMCs were washed twice with MEM and treated with MEM containing $10 \%$ serum obtained from a patient with sepsis. After 24 hours, the amount of NO released from the SMC was measured as nitrite in this medium and in aqueous solution by means of a chemiluminescence detector (Silvers Instruments, Inc., CO). ${ }^{6,7}$ Nitrite concentration was determined using sodium nitrite $\left(\mathrm{NaNO}_{2}\right.$, Wako, Osaka) as the standard. The background signal in the medium was subtracted from each measured value. The NO production was calculated as follows;

$\mathrm{NO}$ production $=$ test value - blank value

Blank means the nitrite from MEM supplemented with serum.

Lipopolysacharide (LPS; Sigma Co Ltd, MO) induced nitrite production from SMC for 24 hours $(0.5 \mathrm{ng} / \mathrm{ml}$ of LPS: $27.0 \pm 4.3 \mathrm{pmol} / \mathrm{well}, 1 \mathrm{ng} / \mathrm{ml}$ of LPS: $40.2 \pm 6.9 \mathrm{pmol} / \mathrm{well})$.

\section{Results}

Sera from patients with sepsis induced NO production from SMC. In Table 1, clinical data on 4 patients with sepsis are shown. None of the patients had hypotension. Three cases showed neutropenia $(<500 / \mu 1)$. The samples from all these patients significantly induced nitrite production in cultured SMC $(5.95 \pm 1.5 \mathrm{pmol} / \mathrm{well}, \quad p<0.05$ vs. normal subjects; $0.50 \pm 0.02 \mathrm{pmol} / \mathrm{well})$. On the other hand, serum obtained from the same patients after the treatment from sepsis did not induce nitrite production in the SMC $(0.86 \pm 0.2 \mathrm{pmol} / \mathrm{well})$, as shown in Fig. 1(A). Furthermore, sera obtained from normal subjects $(N=4)$ also did not increase the nitrite production in the SMC $(0.38 \pm 0.08 \mathrm{pmol} / \mathrm{well})$.

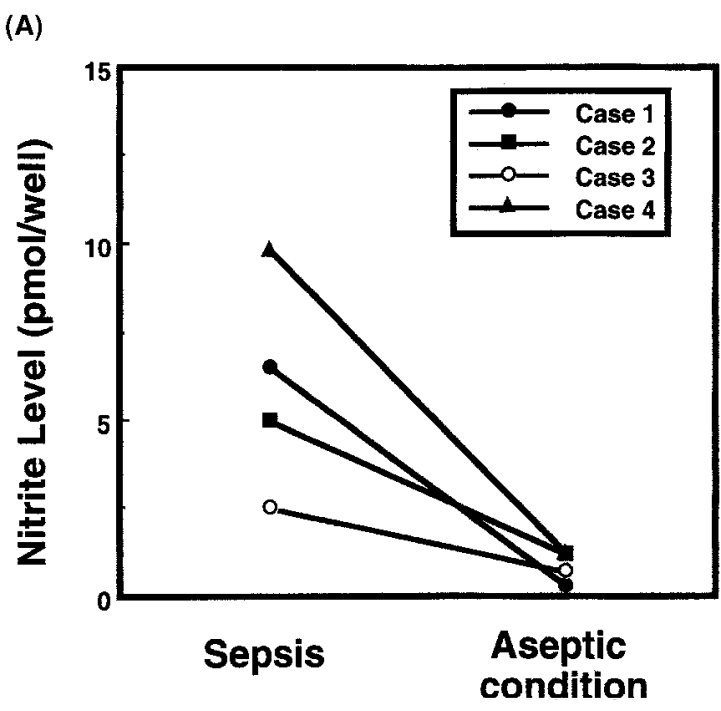

(B)

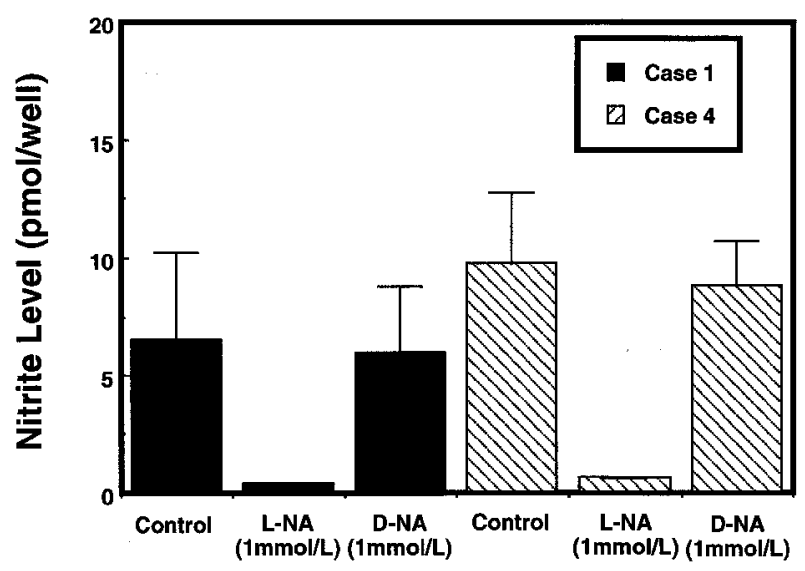

FIG. 1. (A) Nitrite production in vascular smooth muscle cells treated with serum obtained from the patients with sepsis. Vascular smooth muscle cells (SMC) were grown to confluence on a 24-well dish. Nitrite levels were measured in the medium of the SMC treated with the serum for 24 hours, as described in Patients and methods. Four patients (cases 1-4 in the Table 1) were analysed. The data represent the mean of 8 wells. (B) Effect of a nitric oxide synthase inhibitor, L-nitroarginine, on the nitrite levels in the SMC treated with serum obtained from patients with sepsis. Vascular smooth muscle cells (SMC) were grown to confluence on a 24-well dish. Nitrite levels were measured in the medium of the SMC treated with the serum for 24 hours, in the presence or absence of L-nitroarginine $(1 \mathrm{mmol} / \mathrm{L})$ or $\mathrm{D}$-nitroarginine $(1 \mathrm{mmol} / \mathrm{L})$. These experiments were performed for Cases 1 and 4 described in Table 1 . The data represent the means \pm SEM of 8 wells. Each experiment was repeated 3 times. 
Effect of a specific NOS inhibitor on the NO production induced by the septic sera

L-nitroarginine ( $1 \mathrm{mmol} / \mathrm{L})$, a specific NOS inhibitor, was concomitantly added to the cultured SMC treated with MEM containing 10\% sera obtained from the patients with sepsis (cases 1 and 4). L-nitroarginine suppressed the increase in nitrite level as shown in Fig. 1(B). On the other hand, D-nitroarginine, an optical isomer, which does not inhibit NOS activity, did not affect the increase in nitrite level.

\section{Discussion}

L-nitroarginine, but not D-nitroarginine, inhibited the production of nitrite in cultured SMC induced by sera obtained from patients with sepsis, suggesting that the nitrite was derived from iNOS in the SMC. Using the proposed assay technique, the activity of endogenous NO production can be evaluated. Even sera obtained from patients with sepsis who did not have hypotension induced an increase in the nitrite production in the SMC. We measured the nitrite levels in the medium of cultured SMC treated with serum obtained from two patients with septic shock (15.2 and $17.5 \mathrm{pmol} /$ well, respectively). Despite evaluation of only two cases, this assay technique is considered beneficial for the severity of sepsis. It has been previously reported that the plasma nitrite levels increased in patients with sepsis. ${ }^{8}$ However, plasma nitrite is derived from not only endogenous NO, but also from various foods and bacterial products. In sepsis, bacteria induce the release of massive amounts of nitrite in the blood. We consider that the plasma nitrite level does not directly reflect the endogenous NO production.

Our assay method measures only the ability for the endogenous NO production of an individual person. However, there are also some disadvantages of this technique. ${ }^{1}$ The substances that induce NO production are unclear. We consider that various interleukins, such as interleukin 1 and 6 , and so on in the serum may induce iNOS in SMC. ${ }^{2}$ Even in the case of septic shock, the endogenous NO production in SMC is low (pmol/well). Thus, it is possible that SMC are not adequate as target cells. On the other hand, since the NO production in macrophage cell lines is massive, in further experiments, we propose to measure the nitrite levels using macrophage cell lines. Moreover, because only four patients with sepsis were evaluated in this study, we propose to enrol many patients with sepsis and septic shock to evaluate the endogenous NO producing activity in the patients.

\section{References}

1. Glauser MP, Zanetti G, Baumgarner JD, Cohen J. Septic shock: pathogenesis. Lancet 1991; 338: 732-736.

2. Nava E, Palmer RMJ, Moncada S. Inhibition of nitric oxide synthesis in septic shock: How much is beneficial? Lancet 1991; 338: 1555-1557.

3. Petros A, Lamb G, Leone A, Moncada S, Bennett D, Vallance P. Effects of nitric oxide synthase inhibitor in humans with septic shock. Cardiovas Res 1994; 28: 34-39.

4. Groeneveld PH, Kwappenberg KM, Langermans JA, Nibbering PH, Cutis L. Nitric oxide production correlates with renal insufficiency and multiple organ dysfunction syndrome in severe sepsis. Intens Care Med 1996; 22: 1197-1202.

5. Ross R. The smooth muscle cell. II. Growth of smooth muscle cell in culture and formation of elastic fibres. J Cell Biol 1971; 50: 172-186.

6. Brauman RS, Hendrix SA. Nanogram nitrite and nitrate determination in environmental and biological materials by vanadium reduction with chemiluminescence detection. Ann Chem 1989; 51: 2715-2718.

7. Sano M, Sato-Suzuki I, Fujita H, Morita I, Nagao M, Murota S. NO is not involved in the simvastatin induced cell division and differentiation in PC 12 cells. Neurosci Lett 1998; 243: 73-76.

8. Evans T, Carpenter A, Kidderman H, Cohen J. Evidence of increased nitric oxide production in patients with the sepsis syndrome. Circulatory Shock 1993; 41: 77-81.

Received 28 September 2000 accepted after revision 29 October 2000 


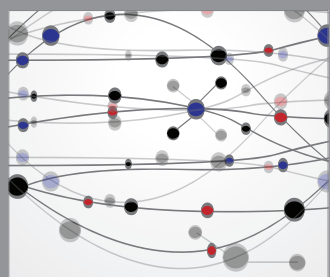

The Scientific World Journal
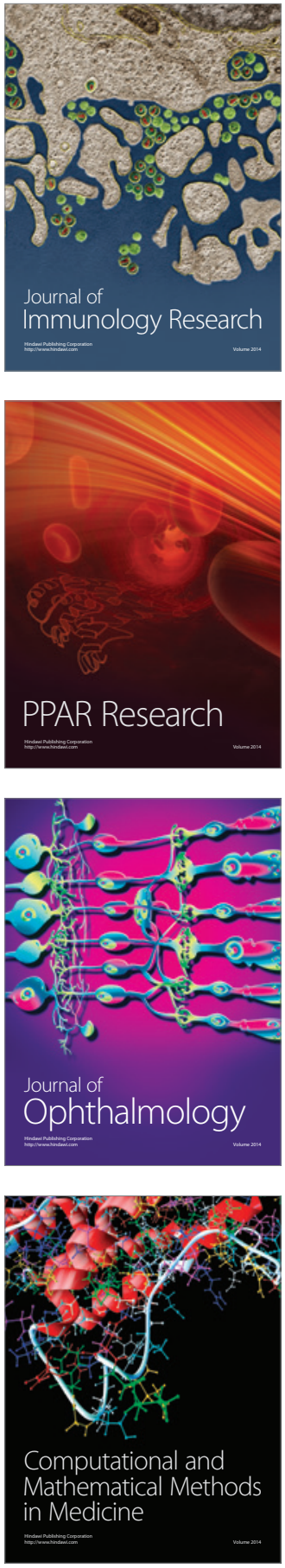

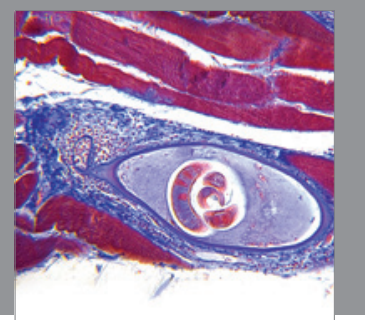

Gastroenterology

Research and Practice
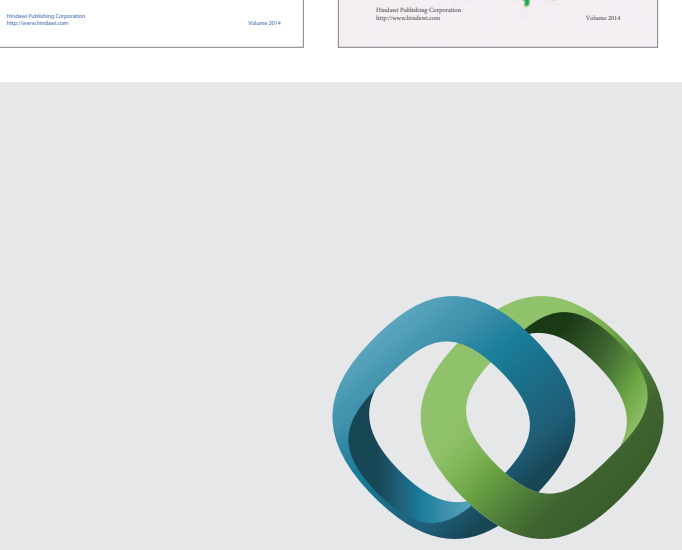

\section{Hindawi}

Submit your manuscripts at

http://www.hindawi.com
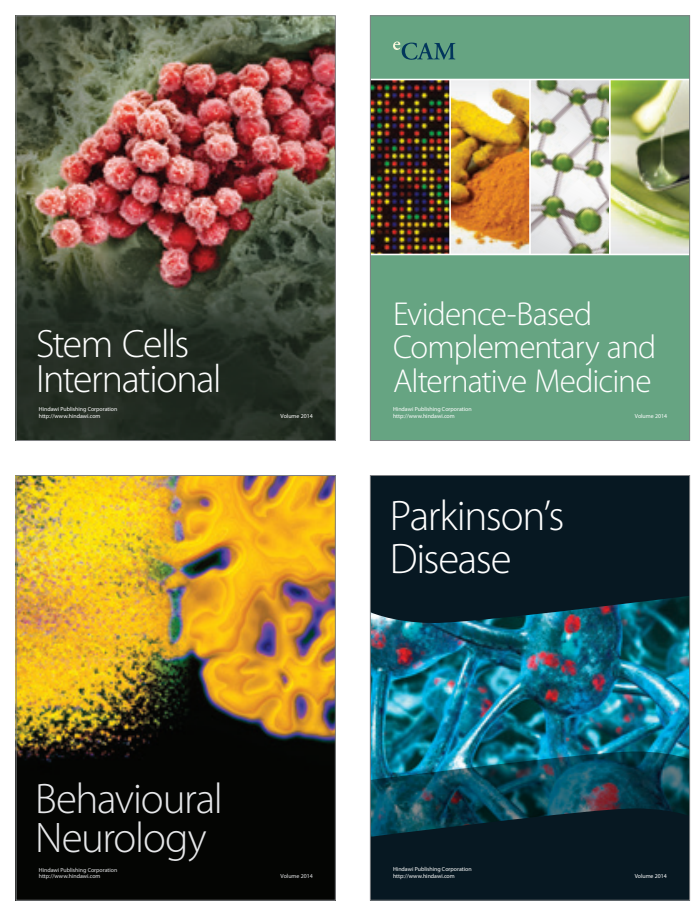

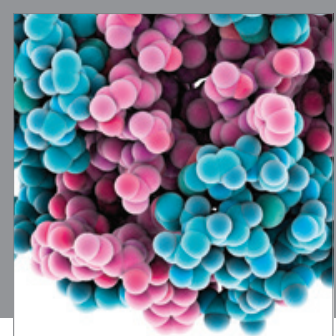

Journal of
Diabetes Research

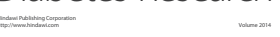

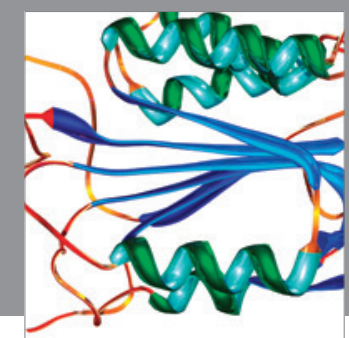

Disease Markers
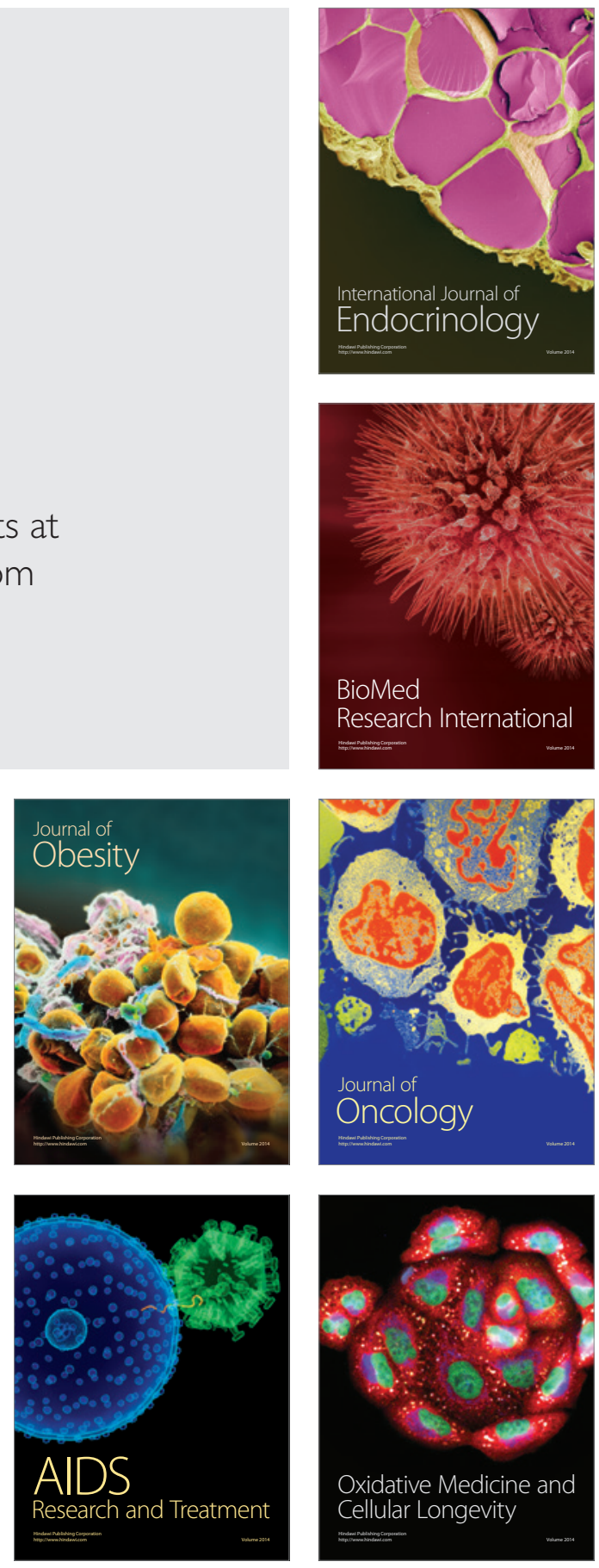